\title{
Analisis Kesesuaian Ekowisata Mangrove Di Desa Taddan Kecamatan Camplong Kabupaten Sampang
}

\section{Analysis Of The Suitability Of Mangrove Ecosystem In Taddan Village, Kecamatan Camplong, Sampang District}

\author{
Maywa Widiya Pratiwi ${ }^{1}$, Firman Farid Muhsoni ${ }^{1)^{*}}$ \\ 1)Program Studi Manajemen Sumberdaya Perairan, Jurusan Kelautan dan Perikanan, Fakultas \\ Pertanian, Universitas Trunojoyo Madura \\ *Penulis Korespondensi : Email: firmanfaridmuhsoni@trunojoyo.ac.id
}

(Diterima September 2021/Disetujui Oktober 2021)

\begin{abstract}
Mangrove forest areas have diverse biodiversity and biota, an area that has the potential to be developed as a marine ecotourism area. The purpose of this study was to determine the tourism suitability index, the carrying capacity of the area, and the carrying capacity of using mangrove ecotourism in Taddan Village, Camplong District, Sampang Regency. Mangrove data collection methods use line transects and plots (Line Transect Plot). The results showed that the types of mangroves in the research location were Rhizophora stylosa, Rhizophora mucronata, Rhizophora apiculata, Sonneratia alba, Avicennia marina, and Aegiceras corniculate. The suitability of the area to be used as a marine ecotourism area in the mangrove category for all stations in suitable conditions. The carrying capacity of an area shows the results of the ability of an area to provide space for the use of 199 people per day, while for per trip as many as 25 people per trip. The carrying capacity of the utilization by considering the area for conservation is $10 \%$, then the yield is 20 people.
\end{abstract}

Keywords: Mangroves, Ecotourism, Area Supporting Capacity

\section{ABSTRAK}

Kawasan hutan mangrove memiliki keanekaragaman hayati dan biota yang beragam, kawasan ini potensial dikembangkan sebagai kawasan ekowisata bahari. Tujuan penelitian ini untuk mengetahui indeks kesesuaian wisata, daya dukung kawasan, dan daya dukung pemanfaatan ekowisata mangrove di Desa Taddan Kecamatan Camplong Kabupaten Sampang. Metode pengambilan data mangrove menggunakan transek garis dan plot (Line Transect Plot). Hasil penelitian mendapatkan jenis mangrove di lokasi penelitian adalah Rhizophora stylosa, Rhizophora mucronata, Rhizophora apiculata, Sonneratia alba, Avicennia marina, dan Aegiceras cornitulatum. Kesesuaian kawasan untuk dimanfaatkan sebagai kawasan ekowisata bahari kategori mangrove untuk semua stasiun pada kondisi sesuai bersyarat. Daya dukung kawasan menunjukkan hasil kemampuan suatu kawasan dalam menyediakan ruang bagi pemanfaatan sebanyak 199 orang per hari, sedangkan untuk per trip sebanyak 25 orang per trip. Daya dukung pemanfaatan dengan mempertimbangkan persentase kawasan untuk konservasi sebesar $10 \%$ maka diperoleh hasil sebanyak 20 orang per hari.

Kata Kunci: Mangrove, Ekowisata, Daya Dukung Kawasan

\section{PENDAHULUAN}

Indonesia merupakan negara yang memiliki hutan mangrove terluas di dunia, jumlah luasnya kurang lebih $25 \%$ luas mangrove yang ada di dunia (Eddy et al., 2016). Wilayah tersebut menjadikan kawasan hutan mangrove yang ada di Indonesia sangat disukai oleh biota dan

To Cite this Paper: Pratiwi, M, W., Muhsoni, F, F., 2021. Analisis Kesesuaian Ekowisata Mangrove Di Desa Taddan Kecamatan Camplong Kabupaten Sampang. Samakia: Jurnal IImu Perikanan, 12 (2): 105-115.

Journal Homepage: https://journal.ibrahimy.ac.id/index.php/JSAPI 
makhluk hidup lainnya. Sehingga wilayah tersebut memiliki keanekaragaman hayati dan biota yang beragam jenisnya dan dapat dikembangkan sebagai kawasan ekowisata bahari. Ekowisata bahari terdiri atas tiga kawasan yaitu kawasan yang berada di atas permukaan laut, kawasan yang berada di bawah laut, dan juga kawasan yang berada di pantai (Yulius et al., 2018). Ekowisata bahari khususnya kawasan yang berada di permukaan laut menyajikan ekosistem mangrove beserta biota yang ada di dalamnya.

Provinsi Jawa Timur memiliki kawasan ekosistem mangrove yang luas, menurut Arisandi, (1999) pada tahun 1982 seluas 7,750 ha, salah satunya di Desa Taddan Kecamatan Camplong Kabupaten Sampang. Sedangkan Muhsoni (2020) menjelaskan Luas Mangrove di Desa Taddan mencapai 48 ha. Wardhaniardhani, (2011) dan Edi et al., (2009) menjelaskan bahwa pengelolaan kawasan mangrove dapat dilakukan dengan membuat kawasan tersebut menjadi kawasan ekowisata. Hal tersebut dapat dilakukan dengan partisipasi masyarakat. Partisipasi masyarakat merupakan faktor yang sangat penting agar ekosistem tersebut dapat berkelanjutan. Kajian kesesuaian wisata sangat diperlukan untuk mengetahui potensi pengembangan kawasan mangrove menjadi area ekowisata. Penelitian ini bertujuan untuk mengetahui indeks kesesuaian wisata, mengetahui daya dukung kawasan, dan mengetahui daya dukung pemanfaatan ekowisata mangrove di Desa Taddan Kecamatan Camplong Kabupaten Sampang.

\section{MATERI DAN METODE}

Penelitian ini dilaksanakan pada bulan Agustus - September 2020. Penelitian ini di laksanakan di Kawasan Mangrove Desa Taddan Kecamatan Camplong Kabupaten Sampang. Lokasi stasiun pengamatan lapang seperti pada gambar 1 . Jumlah stasiun ada 5 , dan masing-masing stasiun ada 2-3 plot, tergantung dari ketebalan mangrove.

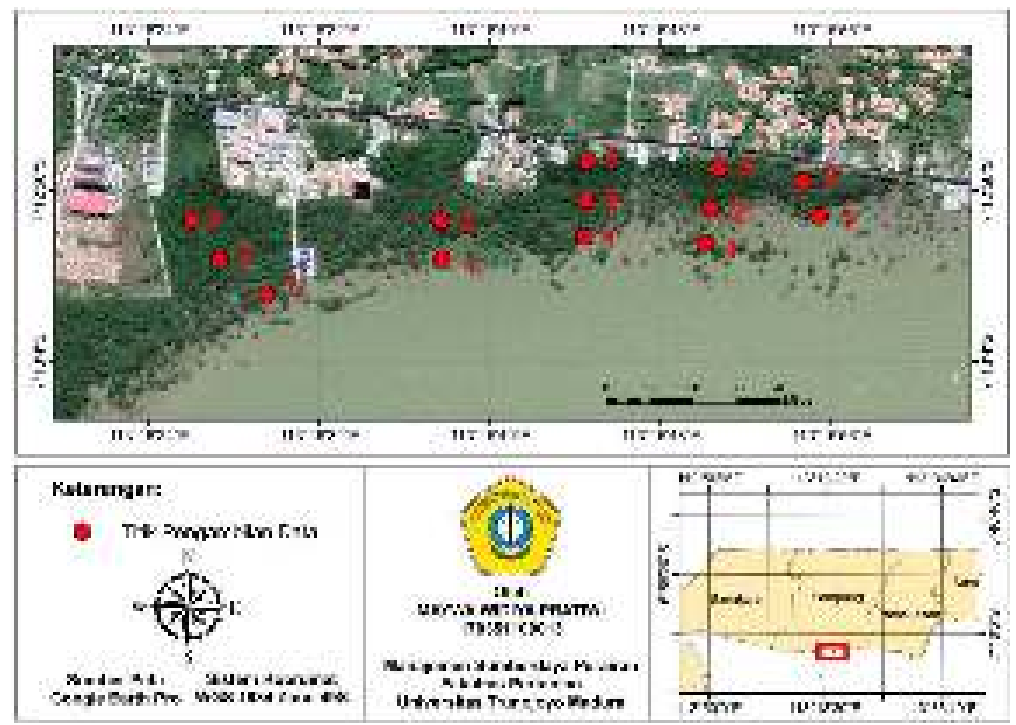

Gambar 1. Peta Lokasi Penelitian

\section{Pengambilan Data Mangrove}

Metode penelitian ini menggunakan transek garis dan plot (Line Transect Plot) (seperti pada gambar 2). Stasiun pengamatan ditentukan dari hasil pertimbangan observasi awal di lapangan (Metternicht, 2003; Kauffman \& Donato, 2012; Hartoko et al., 2015; Hairiah et al., 2001). Prinsip penentuan stasiun dilakukan berdasarkan keterwakilan lokasi mangrove, dimana terdapat 5 stasiun pengamatan. Setiap stasiun terdiri dari 2 atau 3 plot dan satu jalur yang dibentangkan mulai dari batas laut ditemukannya mangrove terakhir sampai batas daratan tumbuhnya mangrove dengan jarak antar plot adalah 20 meter.

To Cite this Paper: Pratiwi, M, W., Muhsoni, F, F., 2021. Analisis Kesesuaian Ekowisata Mangrove Di Desa Taddan Kecamatan Camplong Kabupaten Sampang. Samakia: Jurnal Ilmu Perikanan, 12 (2): 105-115.

Journal Homepage: https://journal.ibrahimy.ac.id/index.php/JSAPI 


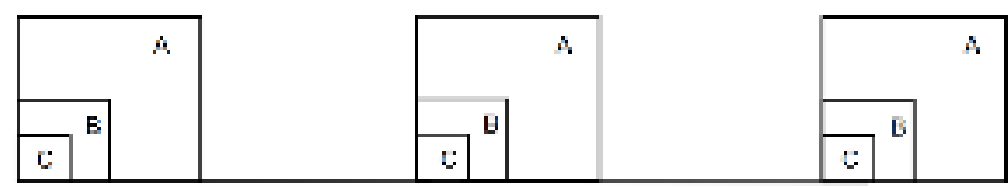

Gambar 2. Desain unit contoh pengamatan vegetasi di lapan dengan metode jalur (Menteri Negara Lingkungan Hidup RI, 2004); (BNS, 2011)

Keterangan Gambar 2 menurut Susanto et al.,( 2013); Syahrial et al.,(2019); Supardjo, (2008) sebagai berikut:

A. Petak (plot) $10 \times 10 \mathrm{~m}^{2}$ merupakan kategori pohon yang memiliki tinggi lebih dari 1,5 m dengan diamater batang $10 \mathrm{~cm}$ atau lebih.

B. Petak (plot) $5 \times 5 \mathrm{~m}^{2}$ merupakan kategori pancang yang memiliki tinggi $1,5 \mathrm{~m}$ sampai anakan yang berdiameter kurang dari $10 \mathrm{~cm}$.

C. Petak (plot) $2 \times 2 \mathrm{~m}^{2}$ merupakan kategori semai yang memiliki tinggi kurang dari 1,5 $\mathrm{m}$ dan keliling $<2 \mathrm{~cm}$.

\section{Analisa Kesesuaian Ekowisata Bahari}

Metode pengambilan data yang digunakan adalah metode analisis kesesuaian wisata kategori mangrove. Kriterian kesesuaian wisata kategori mangrove seperti pada tabel 1 (Solarbesain, (2009); Yulius et al., (2018); Muhsoni, (2017); Anwar, (2011); Kurniawan, (2011); (Yusuf, 2007)).

Tabel 1. Matriks Kesesuaian Wisata Kategori Mangrove

\begin{tabular}{|c|c|c|c|}
\hline Parameter & Bobot & Kategori & Skor \\
\hline \multirow[t]{4}{*}{ Ketebalan mangrove $(\mathrm{m})$} & \multirow{4}{*}{5} & $>500$ & 3 \\
\hline & & $>200-500$ & 2 \\
\hline & & $>50-200$ & 1 \\
\hline & & $<50$ & 0 \\
\hline \multirow{4}{*}{$\begin{array}{l}\text { Kerapatan mangrove }(100 \\
\left.\mathrm{m}^{2}\right)\end{array}$} & \multirow{4}{*}{3} & $>15-20$ & 3 \\
\hline & & $>10-15 ;>20$ & 2 \\
\hline & & $>5-10$ & 1 \\
\hline & & $<5$ & 0 \\
\hline \multirow[t]{4}{*}{ Jenis mangrove } & \multirow{4}{*}{3} & $>5$ & 3 \\
\hline & & $3-5$ & 2 \\
\hline & & $2-1$ & 1 \\
\hline & & 0 & 0 \\
\hline \multirow[t]{4}{*}{ Objek biota } & \multirow{4}{*}{1} & $\begin{array}{l}\text { Ikan, udang, kepiting, moluska, } \\
\text { reptil, burung }\end{array}$ & 3 \\
\hline & & Ikan, udang, kepiting, moluska & 2 \\
\hline & & Ikan dan moluska & 1 \\
\hline & & Salah satu biota air & 0 \\
\hline \multirow[t]{4}{*}{ Pasang surut (m) } & \multirow{4}{*}{1} & $0-1$ & 3 \\
\hline & & $>1-2$ & 2 \\
\hline & & $>2-5$ & 1 \\
\hline & & $>5$ & 0 \\
\hline
\end{tabular}

Keterangan:

To Cite this Paper: Pratiwi, M, W., Muhsoni, F, F., 2021. Analisis Kesesuaian Ekowisata Mangrove Di Desa Taddan Kecamatan Camplong Kabupaten Sampang. Samakia: Jurnal IImu Perikanan, 12 (2): 105-115.

Journal Homepage: https://journal.ibrahimy.ac.id/index.php/JSAPI 


$$
\begin{array}{ll}
\text { Nilai maksimum } & =39 \\
\text { Sesuai } & =75-100 \% \\
\text { Sesuai Bersyarat } & =50-<75 \% \\
\text { Tidak sesuai } & =<50 \% \\
& \text { IKW }=\sum\left(\frac{\mathrm{Ni}}{\mathrm{Nmax}}\right) \times 100 \%
\end{array}
$$

Keterangan:

$\mathrm{IKW} \quad=$ Indeks Kesesuaian Wisata $(\%)$

$\mathrm{Ni} \quad=$ Nilai parameter ke-1 (bobot $\mathrm{x}$ skor)

Nmax = Nilai maksimum dari suatu kategori wisata

\section{Analisa Daya Dukung Kawasan}

\begin{tabular}{|c|c|c|}
\hline Jenis Kegiatan & $\begin{array}{l}\text { Jumlah Pengunjung } \\
\text { (Orang) }\end{array}$ & Keterangan \\
\hline Wisata Mangrove & $50 \mathrm{~m}$ & $\begin{array}{l}\text { Dihitung panjang track setiap } \\
\text { orang dalam } 50 \mathrm{~m}\end{array}$ \\
\hline \multicolumn{3}{|c|}{ Sumber: (Yulius et al., (2018); Ketjulan, (2010); Kurniawan, (2011); Anwar, (2011)) } \\
\hline \multicolumn{3}{|c|}{ Tabel 3. Waktu yang Dibutuhkan (Wp) dan Total Waktu 1 Hari $(\mathrm{Wt})$} \\
\hline Jenis Kegiatan & $\begin{array}{c}\text { Waktu yang di butuhkan } \\
\text { Wp (Jam) }\end{array}$ & $\begin{array}{c}\text { Total waktu } 1 \text { Hari } \\
\text { Wt (Jam) }\end{array}$ \\
\hline Wisata Mangrove & 2 & 8 \\
\hline
\end{tabular}

Analisis daya dukung kawasan membutuhkan informasi Potensi ekologis wisatawan per satuan unit area, total waktu wisata dalam sehari, total waktu jenis kegiatan ekowisata per orang yang dapat dilihat pada tabel 2 dan tabel 3 .

Tabel 2. Potensi Ekologis Wisatawan (K) dan Luas Area (Lt)

Keterangan (Yulius et al., (2018); Ketjulan, (2010); Kurniawan, (2011); Anwar, (2011); (Muhsoni, 2017); Manafi et al., (2009)):

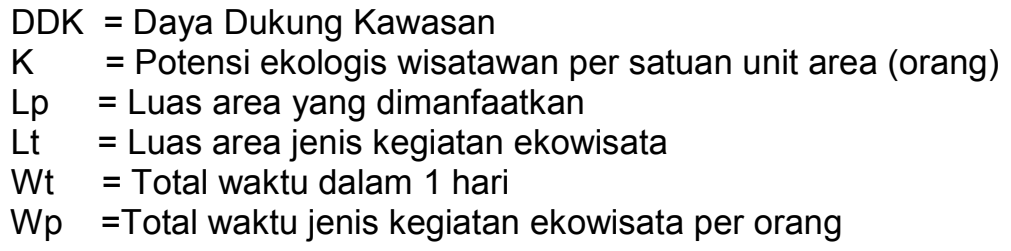

\section{Analisa Daya Dukung Pemanfaatan}

Menurut Yulius et al., (2018); Ketjulan, (2010); Kurniawan, (2011); Anwar, (2011); Muhsoni, (2017); Muhsoni, (2016) analisa daya dukung pemanfaatan menggunakan rumus sebagai berikut:

$$
\mathrm{DDP}=\mathrm{DDK} \times 0,1
$$

Keterangan:

DDP = Daya Dukung Pemanfaatan

DDK = Daya Dukung Kawasan

\section{HASIL DAN PEMBAHASAN}

Kabupaten Sampang memiliki garis pantai terpanjang kedua di wilayah Madura yang terletak di Pantai Camplong. Panjang garis pantai tersebut mencapai $-/+14,07 \mathrm{Km}$. Kecamatan Camplong

To Cite this Paper: Pratiwi, M, W., Muhsoni, F, F., 2021. Analisis Kesesuaian Ekowisata Mangrove Di Desa Taddan Kecamatan Camplong Kabupaten Sampang. Samakia: Jurnal IImu Perikanan, 12 (2): 105-115.

Journal Homepage: https://journal.ibrahimy.ac.id/index.php/JSAPI 
memiliki 14 Desa yang terdiri dari Desa Anggersek, Banjar Tabulu, Banjar Talela, Batu Karang, Dharma Camplong, Dharma Tanjung, Madupat, Pamolaan, Prajjan, Rabasan, Sejati, Taddan, dan juga Tambaan. Selain itu Kecamatan Camplong juga memiliki kawasan mangrove yang cukup luas salah satunya di Desa Taddan Kecamatan Camplong (Agustin et al., 2002). Luas mangrove di Desa Taddan 48 ha, dengan pola distribusi cenderung menyebar dalam kelompok, dengan tingkat keanekaragaman rendah, dan indeks keseragaman seimbang atau terdapat individu yang mendominasi (Muhsoni, 2020).

\section{Analisis Kesesuaian Ekowisata Mangrove}

Ekowisata mangrove merupakan bagian dari ekowisata bahari. Ekowisata bahari sendiri merupakan wisata khusus yang aktifitasnya berkaitan dengan kelautan, yang terdiri dari kawasan permukaan laut, di bawah laut dan di pesisir pantai. Ekowisata mangrove merupakan ekowisata di pesisir pantai. Kegiatan wisata memiliki persyaratan sumberdaya dan lingkungn sesuai objek yang dikembangkan. Persyaratan tersebut berupa parameter fisik dan biologi (Yulius et al., 2018). Parameter kesesuaian ekowisata mangrove adalah ketebalan mangrove, kerapatan mangrove, jenis mangrove, pasang surut dan objek biota.

\section{a. Ketebalan Mangrove}

Ketebalan mangrove di Desa Taddan Kecamatan Camplong Kabupaten Sampang berbeda-beda ketebalannya (gambar 3). Ketebalan mangrove yang berbeda-beda diakibatkan oleh perbedaan tipe pantai pada setiap stasiunnya. Jika pantai bertipe landai maka nilai ketebalannya lebih tinggi daripada tipe pantai curam. Stasiun 1 memiliki ketebalan 206,64 m, stasiun 2 memiliki ketebalan mangrove 167,63 m, stasiun 3 memiliki ketebalan mangrove 167,92 m, stasiun 4 memiliki ketebalan mangrove 231,42 m, dan stasiun 5 memiliki ketebalan mangrove 257,44 m. Rata-rata ketebalan mangrove di lokasi penelitian 206,21 m. Johan et al., (2011) menjelaskan kondisi mangrove yang tebal dapat menjadi daya tarik tersendiri bagi wisatawan dalam segi estetika. Semakin tebal mangrove maka wisatawan atau pengunjung semakin tertarik. Mangrove di Desa Taddan perlu adanya jembatan agar memudahkan para pengunjung menyusuri kawasan wisata mangrove.

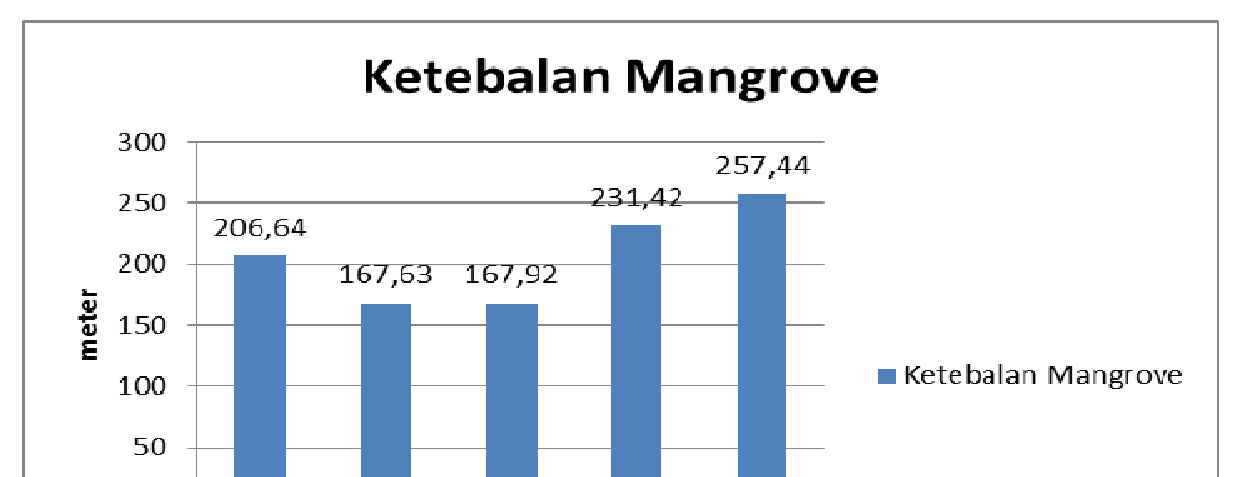

To Cite this Paper: Pratiwi, M, W., Muhsoni, F, F., 2021. Analisis Kesesuaian Ekowisata Mangrove Di Desa Taddan Kecamatan Camplong Kabupaten Sampang. Samakia: Jurnal Ilmu Perikanan, 12 (2): 105-115.

Journal Homepage: https://journal.ibrahimy.ac.id/index.php/JSAPI 


\section{b. Kerapatan Mangrove}

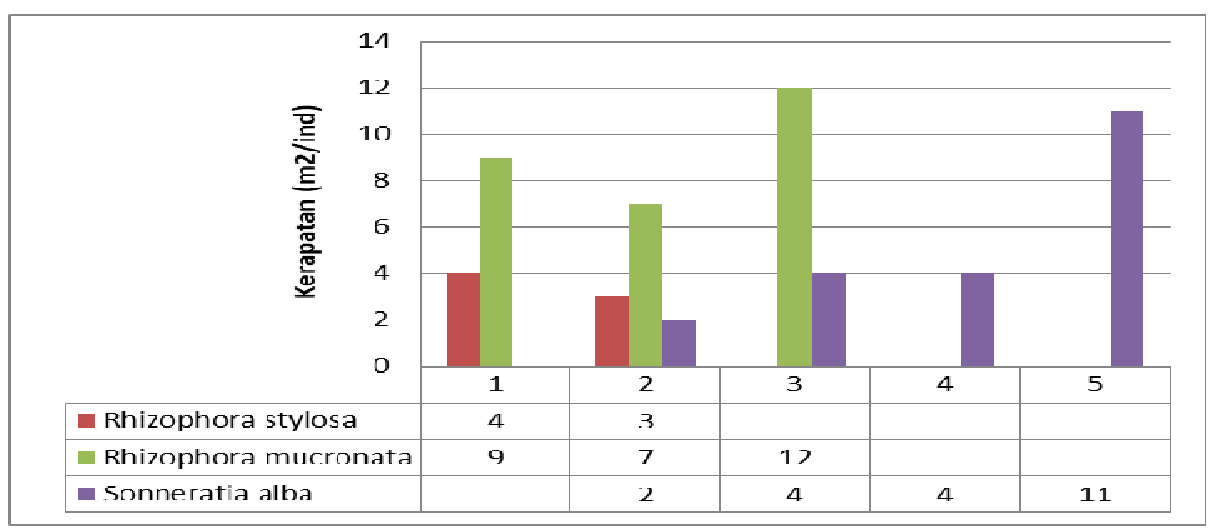

Gambar 4. Kerapatan Mangrove

Kerapatan mangrove di Desa Taddan Kecamatan Camplong Kabupaten Sampang pada stasiun 1 terdapat jenis mangrove Rhizophora stylosa dan Rhizophora mucronata dengan kerapatan masing-masing $4 \mathrm{~m}^{2} /$ ind dan $9 \mathrm{~m}^{2} /$ ind sehingga total kerapatan di stasiun 1 adalah $13 \mathrm{~m}^{2} /$ ind. Pada stasiun 2 ditemukan spesies yaitu Rhizophora stylosa, Rhizophora mucronata dan Sonneratia alba dengan jumlah pohon sebanyak 3,7 , dan 2 , sehingga kerapatan jenisnya berjumlah 12 . Pada stasiun 3 ditemukan spesies Rhizophora mucronata dan Sonneratia alba dengan jumlah pohon sebanyak 12 dan 4, sehingga kerapatan jenisnya berjumlah 16. Pada stasiun 4 ditemukan spesies Sonneratia alba dengan jumlah pohon sebanyak 4, sehingga kerapatan jenisnya berjumlah 4 . Pada stasiun 5 ditemukan spesies Sonneratia alba dengan jumlah pohon sebanyak 11, sehingga kerapatan jenisnya berjumlah 11 . Kerapatan mangrove dapat dilihat pada gambar 4 . Kerapatan mangrove pada indeks kesesuaian wisata memiliki bobot 5. Stasiun 1, 2, 3 dan 5 memiliki kerapatan dalam kategori 10-15 pada matriks indeks kesesuaian wisata sehingga hasil skornya 3. Namun pada stasiun 4 memiliki skor 0 karena masuk dalam kategori $<5$ pada matriks indeks kesesuaian wisata.

\section{c. Jenis Mangrove}

Jenis mangrove yang didentifikasi tidak hanya pada titik plot pengukuran, akan tetapi juga pada sekitar stasiun. Jenis mangrove yang ditemukan di Desa Taddan Kecamatan Camplong Kabupaten Sampang dapat dilihat pada tabel 4. Pada stasiun 1 terdapat 2 jenis mangrove yaitu Rhizophora stylosa dan Rhizophora mucronata. Pada stasiun 2 terdapat 4 jenis mangrove yaitu Rhizophora stylosa, Rhizophora mucronata, Sonneratia alba, dan Rhizophora apiculata. Stasiun 3 terdapat 3 jenis mangrove yaitu Rhizophora mucronata, Sonneratia alba, dan Rhizophora apiculata. Stasiun 4 terdapat 3 spesies mangrove yaitu Rhizophora mucronata, Sonneratia alba, dan Avicennia marina. Stasiun 5 ditemukan 3 spesies mangrove yaitu Rhizophora mucronata, Sonneratia alba, dan Aegiceras cornitulatum.

Tabel 4. Jenis Mangrove yang Ditemukan

\begin{tabular}{cllllll}
\hline \multirow{2}{*}{ NO } & \multicolumn{1}{c}{ Spesies } & $\mathbf{1}$ & $\mathbf{2}$ & $\mathbf{3}$ & $\mathbf{4}$ & $\mathbf{5}$ \\
\cline { 3 - 7 } & & $\sqrt{y}$ & $\sqrt{ }$ & - & - & - \\
\hline 1 & Rhizophora stylosa & $\sqrt{ }$ & $\sqrt{ }$ & $\sqrt{ }$ & $\sqrt{ }$ & $\sqrt{ }$ \\
2 & Rhizophora mucronata & - & $\sqrt{ }$ & $\sqrt{ }$ & - & - \\
3 & Rhizophora apiculata & - & $\sqrt{ }$ & $\sqrt{ }$ & $\sqrt{ }$ & $\sqrt{ }$ \\
4 & Sonneratia alba & - & - & - & $\sqrt{ }$ & - \\
5 & Avicennia marina & - & - & - & - & $\sqrt{ }$ \\
6 & Aegiceras cornitulatum & 2 & 4 & 4 & 3 & 3 \\
\hline
\end{tabular}

To Cite this Paper: Pratiwi, M, W., Muhsoni, F, F., 2021. Analisis Kesesuaian Ekowisata Mangrove Di Desa Taddan Kecamatan Camplong Kabupaten Sampang. Samakia: Jurnal Ilmu Perikanan, 12 (2): 105-115.

Journal Homepage: https://journal.ibrahimy.ac.id/index.php/JSAPI 


\section{d. Objek Biota}

Data objek biota pada indeks kesesuaian mangrove sangat penting karena dapat mempengaruhi nilai estetika kawasan (Yulius et al., 2018). Objek yang digunakan dalam indeks kesesuaian wisata adalah ikan, udang, moluska, reptil, dan burung. Ikan yang ditemukan ada 2 jenis, udang ada 2 jenis, kepiting 3 jenis, moluska ada 20 jenis, reptil ada 1 jenis dan burung ada 4 jenis (pda tabel 5)

Tabel 5. Objek Biota di Desa Taddan

\begin{tabular}{|c|c|c|c|c|c|c|}
\hline \multirow{2}{*}{ NO } & \multirow{2}{*}{ Spesies } & \multicolumn{5}{|c|}{ Stasiun } \\
\hline & & 1 & 2 & 3 & 4 & 5 \\
\hline & Ikan & & & & & \\
\hline 1 & Periopthalmus sp. (Ikan Gelodok) & $\sqrt{ }$ & $\sqrt{ }$ & $\sqrt{ }$ & $\sqrt{ }$ & $\sqrt{ }$ \\
\hline \multirow[t]{2}{*}{2} & Stromateus sp. (Ikan Bawal) & - & - & $\sqrt{ }$ & - & - \\
\hline & Udang & & & & & \\
\hline 1 & Penaeus merguiensis (Udang Putih) & $\sqrt{ }$ & $\sqrt{ }$ & $\sqrt{ }$ & $\sqrt{ }$ & $\sqrt{ }$ \\
\hline \multirow[t]{2}{*}{2} & Penaeus monodon (Udang Windu) & - & $\sqrt{ }$ & $\sqrt{ }$ & - & $\sqrt{ }$ \\
\hline & Kepiting & & & & & \\
\hline 1 & Scylla sp. (Kepiting Bakau) & $\sqrt{ }$ & $\sqrt{ }$ & $\sqrt{ }$ & $\sqrt{ }$ & $\sqrt{ }$ \\
\hline 2 & Uca sp. (Kepiting Biola) & - & $\sqrt{ }$ & - & $\sqrt{ }$ & - \\
\hline \multirow[t]{2}{*}{3} & Portunidae pelagicus (Rajungan) & - & - & $\sqrt{ }$ & - & - \\
\hline & Moluska & & & & & \\
\hline 1 & Cerithideopsilla alata & $\sqrt{ }$ & $\sqrt{ }$ & $\sqrt{ }$ & $\sqrt{ }$ & $\sqrt{ }$ \\
\hline 2 & Cerithidiopsis malayensis & $\sqrt{ }$ & $\sqrt{ }$ & $\sqrt{ }$ & - & - \\
\hline 3 & Nerita articulata & $\sqrt{ }$ & $\sqrt{ }$ & $\sqrt{ }$ & - & $\sqrt{ }$ \\
\hline 4 & Nerita violacea & $\sqrt{ }$ & - & - & - & - \\
\hline 5 & Gafrarium pectinatum & $\sqrt{ }$ & - & - & - & - \\
\hline 6 & Gafrarium tumidum & $\sqrt{ }$ & $\sqrt{ }$ & $\sqrt{ }$ & - & - \\
\hline 7 & Rhinoclavis sinensis & $\sqrt{ }$ & $\sqrt{ }$ & $\sqrt{ }$ & - & - \\
\hline 8 & Rhinoclavis aspera & $\sqrt{ }$ & $\sqrt{ }$ & - & - & - \\
\hline 9 & Littoraria undolata & $\sqrt{ }$ & - & $\sqrt{ }$ & $\sqrt{ }$ & $\sqrt{ }$ \\
\hline 10 & Morula margariticula & $\sqrt{ }$ & $\sqrt{ }$ & $\sqrt{ }$ & $\sqrt{ }$ & - \\
\hline 11 & Circe scripta & $\sqrt{ }$ & $\sqrt{ }$ & - & - & - \\
\hline 12 & Ostrea sp. & $\sqrt{ }$ & - & $\sqrt{ }$ & $\sqrt{ }$ & \\
\hline 13 & Trachycardium rugosum & $\sqrt{ }$ & - & - & - & - \\
\hline 14 & Polinices tumidus & $\sqrt{ }$ & $\sqrt{ }$ & - & $\sqrt{ }$ & - \\
\hline 15 & Tellina sp. & $\sqrt{ }$ & $\sqrt{ }$ & $\sqrt{ }$ & - & - \\
\hline 16 & Cassidula aurisfelis & - & $\sqrt{ }$ & $\sqrt{ }$ & $\sqrt{ }$ & $\sqrt{ }$ \\
\hline 17 & Telescopium telescopium & - & $\sqrt{ }$ & $\sqrt{ }$ & $\sqrt{ }$ & $\sqrt{ }$ \\
\hline 18 & Isognomon sp & - & $\sqrt{ }$ & - & - & - \\
\hline 19 & Cerithidea obtusa & - & - & $\sqrt{ }$ & - & $\sqrt{ }$ \\
\hline \multirow[t]{2}{*}{20} & Nassarius albescens & - & - & $\sqrt{ }$ & - & - \\
\hline & Reptil & & & & & \\
\hline \multirow[t]{2}{*}{1} & Veranus sp. (Biawak) & $\sqrt{ }$ & $\sqrt{ }$ & $\sqrt{ }$ & $\sqrt{ }$ & $\sqrt{ }$ \\
\hline & Burung & & & & & \\
\hline 1 & Corvus enca unicolor (Burung Gagak) & $\sqrt{ }$ & - & $\sqrt{ }$ & - & - \\
\hline
\end{tabular}

To Cite this Paper: Pratiwi, M, W., Muhsoni, F, F., 2021. Analisis Kesesuaian Ekowisata Mangrove Di Desa Taddan Kecamatan Camplong Kabupaten Sampang. Samakia: Jurnal IImu Perikanan, 12 (2): 105-115.

Journal Homepage: https://journal.ibrahimy.ac.id/index.php/JSAPI 
2 Ardeidae (Burung Kuntul)

3 Leptoptilos javanicus (Burung Bangau)

$4 \quad$ Oriolus chinensis (Burung Kepodang)

\section{e. Pasang Surut}

Data analisis pasang surut air laut menunjukkan bahwa pasang tertinggi adalah pada bulan Januari, Juni, Juli, September, November, dan Desember dengan ketinggian 2,5 m. Sedangkan pasang surut terendah terjadi pada bulan Februari, Maret, April, Agustus, September, Oktober, dan November dengan ketinggian $0 \mathrm{~m}$. Hal ini menunjukkan bahwa ketinggian pasang surut di Desa Taddan rata-rata setinggi $1,4 \mathrm{~m}$. Nilai pasang surut tersebut sesuai dengan kriteria matriks ekowisata bahari kategori mangrove dan memiliki skor 2. Pasang surut di Desa Taddan merupakan jenis pasang surut campuran condong ke harian ganda. Hal ini karena pasang surut terjadi 2 kali pasang dan 2 kali surut dalam 1 hari yang memiliki ketinggian yang hampir sama.

\section{Indeks Kesesuaian Wisata}

Indeks kesesuaian wisata (IKW) pada stasiun 1 memiliki nilai sebesar $59 \%$, stasiun 2 sebesar $54 \%$, stasiun 3 dan stasiun 5 sebesar $67 \%$, dan stasiun 4 memiliki nilai sebesar $51 \%$ (seperti pada tabel 6). Nilai indeks kesesuaian wisata (IKW) pada setiap stasiun berbeda namun masih pada kelas yang sama, yaitu kelas kesesuaian sesuai bersyarat. Yang berarti bahwa kawasan tersebut masih bisa untuk dijadikan sebagai kawasan ekowisata mangrove namun masih dengan pertimbangan yang besar. Menurut Nugraha et al., (2013) kawasan yang memiliki kelas sesuai bersyarat mempunyai faktor pembatas atau kendala yang masih dapat mendukung adanya kegiatan ekowisata. Kendala tersebut akan menurunkan produktivitas, oleh karena itu untuk melaksanakan kegiatan ekowisata, kendala tersebut harus lebih diperhatikan guna menjaga ekosistem. Laapo, (2010) menjelaskan pada kategori sesuai bersyarat untuk ekowisata mangrove dapat ditingkatkan menjadi sesuai jika dilakukan upaya konservasi dan rehabilitasi melalui pelibatan masyarakat lokal.

Syarat yang harus dilakukan agar menjadi sesuai untuk kawasan ekowisata mangrove di Desa Taddan adalah dengan meningkatkan salah satu parameter seperti nilai dari ketebalan, kerapatan, atau jenis mangrove dapat diatasi dengan cara melakukan penanaman dan melakukan pembatasan zonasi hutan mangrove. Sehingga setelah dihitung dengan rumus indeks kesesuaian wisata (IKW) kawasan mangrove Desa Taddan layak untuk dijadikan kawasan ekowisata jika salah satu atau beberapa parameter ditingkatkan hingga memperoleh nilai indeks kesesuaian wisata (IKW) sebesar $>75 \%$. Hasil dari indeks kesesuaian wisata (IKW) ini sesuai dengan persepsi masyarakat Desa Taddan yang menginginkan kawasan tersebut untuk dijadikan sebagai kawasan ekowisata. Menurut penduduk asli Desa Taddan hal positif yang didapat dari diadakannya kegiatan ekowisata ini ada untuk meningkatkan pendapatan masyarakat setempat dengan cara membuka rumah makan, menyediakan penginapan, menjadi tour guide, dan juga menjual makanan atau barang khas Desa Taddan Kecamatan Camplong Kabupaten Sampang.

Tabel 6. Matriks Kesesuaian Wisata

\begin{tabular}{ccc}
\hline Stasiun & IKW (\%) & Kelas \\
\hline 1 & $59 \%$ & Sesuai Bersyarat \\
2 & $54 \%$ & Sesuai Bersyarat \\
3 & $67 \%$ & Sesuai Bersyarat \\
4 & $51 \%$ & Sesuai Bersyarat \\
5 & $67 \%$ & Sesuai Bersyarat \\
\hline
\end{tabular}

\section{Analisa Daya Dukung Kawasan}

Daya dukung kawasan atau kemampuan kawasan dalam menyediakan ruang untuk pemafaatan tanpa mengurangi kemamapuan kawasan tersebut (Muhsoni, 2016b; Anwar, 2011). Daya dukung kawasan juga merupakan acuan untuk menghitung jumlah wisatawan atau pengunjung yang ingin mengunjungi kawasan tertentu. Nugraha et al., (2013) dan Yulius et al., (2018) menjelaskan bahwa

To Cite this Paper: Pratiwi, M, W., Muhsoni, F, F., 2021. Analisis Kesesuaian Ekowisata Mangrove Di Desa Taddan Kecamatan Camplong Kabupaten Sampang. Samakia: Jurnal IImu Perikanan, 12 (2): 105-115.

Journal Homepage: https://journal.ibrahimy.ac.id/index.php/JSAPI 
daya dukung merupakan konsep dasar yang dikembangkan untuk mengelola sumber daya alam dan lingkungan yang berkelanjutan melalui kemampuannya. Konsep daya dukung terutama dikembangkan untuk mencegah terjadinya kerusakan atau degradasi sumber daya alam dan lingkungan, sehingga kelestarian, keberadaan dan fungsinya dapat terwujud, sedangkan masyarakat atau penggunanya tetap sejahtera atau tidak rusak. Anwar, (2011) menjelaskan bahwa potensi ekologis pengunjung juga ditentukan oleh kondisi sumberdaya di kawasan dan jenis kegiatan yang dikembangkan.Pengunjung memerlukan ruang gerak yang cukup luas dalam melakukan kegiatan wisata bahari.

Hasil analisis daya dukung kawasan bisa dilihat pada tabel 7. Luas area hutan mangrove 48,03 ha. Panjang track atau jalur yang direncanakan adalah sepanjang $2495 \mathrm{~m}$ (gambar 5). Pengunjung atau wisatawan yang mengunjungi ekowisata mangrove per hari maksimal sebanyak 199 orang per hari, dalam sehari lokasi ekowisata ini maksimal pengunjung sebanyak 199 orang.

Tabel 7. Nilai Daya Dukung Kawasan Kategori Mangrove per Hari

\begin{tabular}{ccccc}
\hline $\begin{array}{c}\text { Lt (Luas } \\
\text { Area) }(\mathrm{m})\end{array}$ & $\begin{array}{c}\text { Lp (Luas Area } \\
\text { yang } \\
\text { Dimanfaatkan) }(\mathrm{m})\end{array}$ & $\begin{array}{c}\text { Wt (Waktu yang } \\
\text { Disediakan dalam 1 } \\
\text { Hari) (jam) }\end{array}$ & $\begin{array}{c}\text { Wp (Waktu yang } \\
\text { Dihabiskan } \\
\text { Wisatawan) (jam) }\end{array}$ & DDK \\
\hline 50 & $2495 \mathrm{~m}$ & 8 & 2 & 199
\end{tabular}

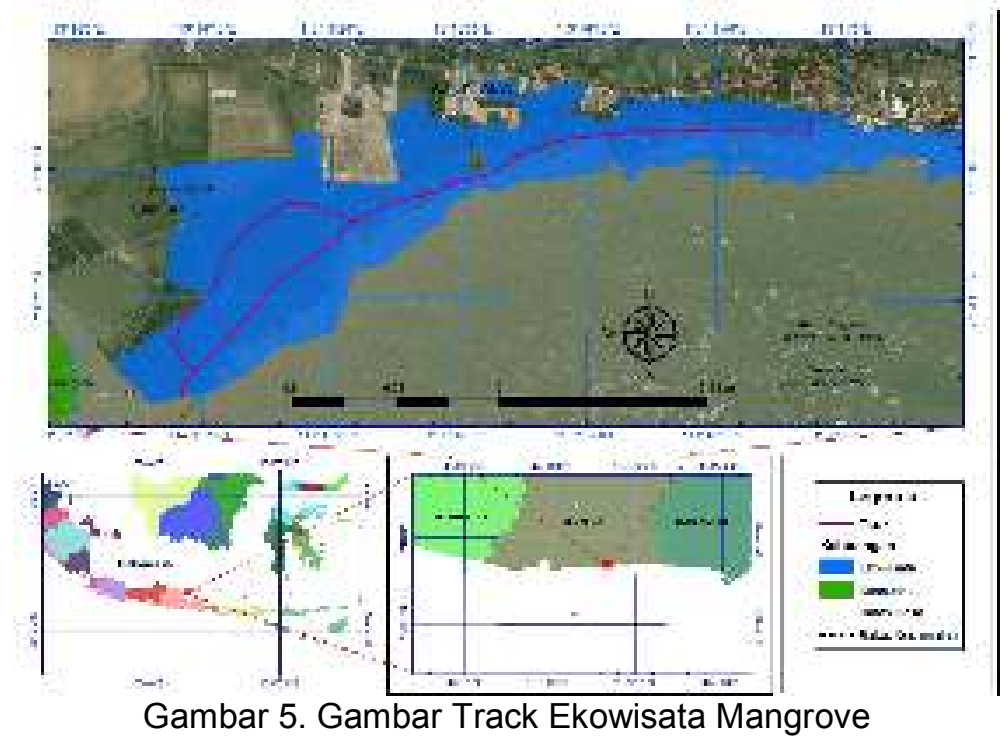

\section{Analisa Daya Dukung Pemanfaatan}

Nilai daya dukung pemanfaatan (DDP) dengan mempertimbangkan persentase kawasan untuk area konservasi $10 \%$. Hal ini dilakukan untuk memperketat pengelolaan agar menekan dampak yang ditimbulkan oleh pemanfaatan wisata (Kurniawan, 2011; Muhsoni, 2016a). Hasil daya dukung pemanfaatan di Desa Taddan sebanyak 20 orang per hari (tabel 9). Seperti halnya pada penelitian Romadhon et al., (2013) menjelaskan nilai DDK pada kawasan mangrove di Pulau Sapeken 321.000 orang per hari karena pengelolaan jumlah pengunjung ini dibatasi karena untuk melindungi, peningkatan kenyamanan, serta kepuasan bagi pengunjung ekowisata mangrove

Tabel 9. Nilai Daya Dukung Pemanfaatan Kategori Mangrove

\begin{tabular}{ccc}
\hline DDK & 0,1 & Hasil \\
\hline 199 & 0,1 & 20 \\
\hline
\end{tabular}

To Cite this Paper: Pratiwi, M, W., Muhsoni, F, F., 2021. Analisis Kesesuaian Ekowisata Mangrove Di Desa Taddan Kecamatan Camplong Kabupaten Sampang. Samakia: Jurnal Ilmu Perikanan, 12 (2): 105-115.

Journal Homepage: https://journal.ibrahimy.ac.id/index.php/JSAPI 


\section{KESIMPULAN}

Berdasarkan hasil penelitian di Desa Taddan Kecamatan Camplong Kabupaten Sampang dapat disimpulkan sebagai berikut:

1. Kesesuaian kawasan untuk dimanfaatkan sebagai kawasan ekowisata bahari kategori mangrove untuk semua stasiun pada kondisi sesuai bersyarat.

2. Daya dukung kawasan menunjukkan hasil kemampuan suatu kawasan dalam menyediakan ruang bagi pemanfaatan sebanyak 199 orang per hari, sedangkan untuk per trip sebanyak 25 orang per trip.

3. Daya dukung pemanfaatan dengan mempertimbangkan persentase kawasan untuk konservasi sebesar $10 \%$ maka diperoleh hasil sebanyak 20 orang per hari.

\section{DAFTAR PUSTAKA}

Agustin, Y. L., Muryono, M., \& Purnobasuki, H. (2002). Estimasi Stok Karbon Pada Tegakan Pohon Rhizophora stylosa Di Pantai Talang Iring, Pamekasan Madura. OCTOBER 2011.

Anwar, R. (2011). Pengembangan dan Keberlanjutan Wisata Bahari di Wilayah Pesisir dan PulauPulau Kecil Kota Makasar. Institut Pertanian Bogor.

Arisandi, P. (1999). Studi Struktur Komunitas dan Keanekaragaman Mangrove Berdasarkan Tipe Perubahan Garis Pantai di Pantai Utara Jawa Timur.

BNS. (2011). SNI 7724 : Pengukuran dan penghitungan cadangan karbon - Pengukuran lapangan untuk penaksiran cadangan karbon hutan (ground based forest carbon accounting ). Badan Standardisasi Nasional.

Eddy, S., Mulyana, A., Ridho, M. R., \& Iskandar, I. (2016). Dampak Aktivitas Antropogenik Terhadap Degradasi Hutan Mangrove Di Indonesia. Jurnal Lingkungan Dan Pembangunan, 2(2), 292-306. https://doi.org/10.31219/osf.io/xd9cb

Edi, M., Okik Hendriyanto, C., \& Nur, F. (2009). Konservasi Hutan Mangrove Sebagai Ekowisata. Envirotek: Jurnal IImiah Teknik Lingkungan, 1, 51-57.

Hairiah, K., Sitompul, S., van Noordwijk, M., \& Palm, C. (2001). Methods for sampling carbon stocks above and below ground. International Centre for Research in Agroforestry, Bogor, Indonesia, ASB Lecture Note 4B, pp.25.

http://www.asb.cgiar.org/PDFwebdocs/LectureNotes/ASB-LN-4B-Hairiah-et-al-2001-Methodssampling-carbon-stocks.pdf.

Hartoko, A., Chayaningrum, S., Febrianti, D. A., \& Ariyanto, D. (2015). Carbon Biomass Algorithms Development for Mangrove Vegetation in Kemujan, Parang Island Karimunjawa National Park and Demak Coastal Area - Indonesia. Procedia Environmental Sciences, 23, 39-47. https://doi.org/10.1016/j.proenv.2015.01.007

Johan, Y., Yulianda, F., Siregar, V. P., \& Karlina, I. (2011). Pengembangan Wisata Baharidalam Pengelolaan Sumberdaya Pulau-Pulau Kecil Berbasis Kesesuaian Dan Daya Dukung. Seminar Nasional Pengembangan Pulau-Pulau Kecil Dari Aspek Perikanan Kelautan Dan Pertanian, 119-129.

http://dx.doi.org/10.1016/j.cirp.2016.06.001\%0Ahttp://dx.doi.org/10.1016/j.powtec.2016.12.05 5\%0Ahttps://doi.org/10.1016/j.ijfatigue.2019.02.006\%0Ahttps://doi.org/10.1016/j.matlet.2019. 04.024\%0Ahttps://doi.org/10.1016/j.matlet.2019.127252\%0Ahttp://dx.doi.o

Kauffman, J., \& Donato, D. (2012). Protocols for the measurement, monitoring and reporting of structure, biomass and carbon stocks in mangrove forests. In Center for International Forestry: Vol. Working pa. https://doi.org/10.17528/cifor/003749

Ketjulan, R. (2010). Daya dukung perairan pulau hari sebagai obyek ekowisata bahari. 14(2), 195204.

Kurniawan, F. (2011). Pemanfaatan Sumberdaya Pulau Kecil Untuk Wisata Berkelanjutan (Studi

To Cite this Paper: Pratiwi, M, W., Muhsoni, F, F., 2021. Analisis Kesesuaian Ekowisata Mangrove Di Desa Taddan Kecamatan Camplong Kabupaten Sampang. Samakia: Jurnal IImu Perikanan, 12 (2): 105-115.

Journal Homepage: https://journal.ibrahimy.ac.id/index.php/JSAPI 
Kasus Pulau Sepanjang, Kabupaten Sumenep, Propinsi Jawa Timur). Thesis.

Laapo, A. (2010). Optimasi Pengelolaan Ekowisata Pulau-Pulau Kecil (Kasus Gugus Pulau Togean Taman Nasional Kepulauan Togean). Institut Pertanian Bogor.

Manafi, M. R., Fahrudin, A., Bengen, D. G., \& Boer, M. (2009). Aplikasi Konsep Daya Dukung untuk Pembangunan Berkelanjutan di Pulau Kecil (Studi Kasus Gugus Pulau Kaledupa, Kabupaten Wakatobi). Jurnal Imu-IImu Perairan Dan Perikanan Indonesia, 16(1), 63-71.

Menteri Negara Lingkungan Hidup RI. (2004). Kepmen Lingkungan Hidup No. 201 Tahun 2004.

Metternicht, G. (2003). Vegetation indices derived from high-resolution airborne videography for precision crop management. International Journal of Remote Sensing, 24(14), 2855-2877. https://doi.org/10.1080/01431160210163074

Muhsoni, F. F. (2016a). Analisi Daya Dukung Pemanfaatan Pulau Gili Labak dengan Menggunakan Sistem Informasi Geografis. Seminar Nasional Perikanan Dan Kelautan VI FPIK UB, 1-6.

Muhsoni, F. F. (2016b). Modelling Of Utilization Carrying Capacity Of Sapudi Island Using. Jurnal Kelautan, 9(1), 73-84.

Muhsoni, F. F. (2017). Potensi dan Pengelolaan Pulau Gili Gili Labak. UTM PRESS.

Muhsoni, F. F. (2020). Karakteristik Kondisi Mangrove di Desa Taddan Kabupaten Sampang. Rekayasa, 13(3), 236-269. https://doi.org/10.21107/rekayasa.v13i3.9146

Nugraha, H. P., Indarjo, A., \& Helmi, M. (2013). Studi Kesesuaian dan Daya Dukung Kawasan untuk Rekreasi Pantai di Pantai Panjang Kota Bengkulu. Journal Of Marine Research, 2(2), 130-139.

Romadhon, A., Yulianda, F., Bengen, D. G., \& Adrianto, L. (2013). Perencanaan Pembangunan Gugus Pulau Sapeken Secara Berkelanjutan: Penilaian Daya Dukung Kawasan Bagi Pengembangan Wisata. Jurnal Tataloka, 15(3), 218. https://doi.org/10.14710/tataloka.15.3.218-234

Solarbesain, S. (2009). Pengelolaan Sumberdaya Pulau Kecil Untuk Ekowisata Bahari Berbasis Kesesuaian Dan Daya Dukung. Institute Pertanian Bogor.

Supardjo, M. N. (2008). Identification Of Mangrove Vegetation In South Segoro Anak, National Sanctuary Of Alas Purwo, Banyuwangi, East Java. Jurnal Saintek Perikanan, 3(2), 9-15.

Susanto, A. H., Soedarti, T., \& Purnobasuki, H. (2013). Struktur Komunitas Mangrove Di Sekitar Jembatan Suramadu Sisi Surabaya. Bioscientiae, 10(1), 1-10.

Syahrial, Saleky, D., Pangaribuan, R. D., Leatemia, S. P. O., \& Putri, N. R. (2019). Status Biota Penempel Pasca Penanaman Mangrove Rhizophora Spp . di Kepulauan Seribu : Studi Kasus Filum Moluska. Journal of Fisheries and Marine Research, 3(2), 172-182.

Wardhaniardhani, M. K. (2011). Kawasan Konservasi Mangrove: Suatu Potensi Ekowisata. Jurnal KELAUTAN, 4(1), 60-79.

Yulius, Rahmania, R., Kadarwati, U. R., Ramdhan, M., Khairunnisa, T., Saepuloh, D., Subandriyo, J., \& Tussadiah, A. (2018). Buku Panduan (Kriteria Penetapan Zona Ekowisata Bahari) (F. Yuliand, H. A. Susanto, R. Ardiwidjaja, \& E. Widjanarko (eds.)). IPB Press. https://doi.org/10.5281/zenodo.1412165

Yusuf, M. (2007). Kebijakan Pengelolaan Sumberdaya Pesisir dan Laut Kawasan Taman Nasional Karimunjawa Secara Berkelanjutan. 284.

To Cite this Paper: Pratiwi, M, W., Muhsoni, F, F., 2021. Analisis Kesesuaian Ekowisata Mangrove Di Desa Taddan Kecamatan Camplong Kabupaten Sampang. Samakia: Jurnal IImu Perikanan, 12 (2): 105-115.

Journal Homepage: https://journal.ibrahimy.ac.id/index.php/JSAPI 